\title{
Cardiac structure and function after revascularization versus medical therapy for renal artery stenosis: the ASTRAL heart echocardiographic sub-study
}

Darren Green ${ }^{1 *}$, Diana Vassallo ${ }^{1}$, Kelly Handley ${ }^{2}$, Natalie Ives ${ }^{2}$, Keith Wheatley ${ }^{2}$, Constantina Chrysochou ${ }^{1}$, Janet Hegarty', Julian Wright ${ }^{3}$, Jon Moss ${ }^{4}$, Rajan K. Patel ${ }^{4}$, Chris Deighan ${ }^{5}$, John Webster ${ }^{6}$, Peter Rowe ${ }^{7}$, Sue Carr ${ }^{8}$, Jenny Cross $^{9}$, Jamie O'Driscoll ${ }^{10}$, Raj Sharma ${ }^{10}$, Patrick Mark ${ }^{11}$ and Philip A. Kalra ${ }^{1}$

\begin{abstract}
Background: The ASTRAL trial showed no difference in clinical outcomes between medical therapy and revascularization for atherosclerotic renal vascular disease (ARVD). Here we report a sub-study using echocardiography to assess differences in cardiac structure and function at 12 months.
\end{abstract}

Methods: ASTRAL patients from 7 participating centres underwent echocardiography at baseline and 12 months after randomisation. Changes in left ventricular ejection fraction (LVEF), left ventricular mass (LVM), left atrial diameter (LAD), aortic root diameter (AoRD), E:A, and E deceleration time (EDT) were compared between study arms. Analyses were performed using t-tests and multivariate linear regression.

Results: Ninety two patients were included (50 medical versus 42 revascularization). There was no difference between arms in any baseline echocardiographic parameter. Comparisons of longitudinal changes in echocardiographic measurements were: $\delta$ LVEF medical $0.8 \pm 8.7 \%$ versus revascularization $-2.8 \pm 6.8 \%$ ( $p=0.05$ ), $\delta L V M-2.9 \pm 33$ versus $-1.7 \pm 39 \mathrm{~g}(p=0.9), \delta L A D 0.1 \pm 0.4$ versus $0.01 \pm 0.5 \mathrm{~cm}(p=0.3), \delta A \circ R D 0.002 \pm 0.3$ versus $0.06 \pm 0.3 \mathrm{~cm}(p=0.4), \delta \mathrm{E}: \mathrm{A}-0.0005 \pm 0.6$ versus $0.03 \pm 0.7(p=0.8), \delta \mathrm{EDT}-1.1 \pm 55.5$ versus $-9.0 \pm 70.2 \mathrm{~ms}(p=0.6)$. In multivariate models, there were no differences between treatment groups for any parameter at 12 months. Likewise, change in blood pressure did not differ between arms (mean $\delta$ systolic blood pressure medical $0 \mathrm{mmHg}$ [range -56 to +54$]$, revascularization $-3 \mathrm{mmHg}[-61$ to +59$], p=0.60)$.

Conclusions: This sub-study did not show any significant differences in cardiac structure and function accompanying renal revascularization in ASTRAL. Limitations include the small sample size, the relative insensitivity of echocardiography, and the fact that a large proportion of ASTRAL patient population had only modest renal artery stenosis as described in the main study.

Keywords: Renal artery stenosis, Revascularization, Echocardiography, Left ventricular hypertrophy, Randomized controlled trial

\footnotetext{
* Correspondence: darrengreen@doctors.org.uk; darren.green@srft.nhs.uk 1 Department of Renal Medicine, Salford Royal NHS Foundation Trust, Stott Lane, Salford M6 8HD, UK

Full list of author information is available at the end of the article
}

(c) The Author(s). 2019 Open Access This article is distributed under the terms of the Creative Commons Attribution 4.0 International License (http://creativecommons.org/licenses/by/4.0/), which permits unrestricted use, distribution, and reproduction in any medium, provided you give appropriate credit to the original author(s) and the source, provide a link to the Creative Commons license, and indicate if changes were made. The Creative Commons Public Domain Dedication waiver (http://creativecommons.org/publicdomain/zero/1.0/) applies to the data made available in this article, unless otherwise stated. 


\section{Background}

The presence of atherosclerotic renovascular disease (ARVD) in patients with chronic kidney disease (CKD) presents an increased risk of cardiovascular morbidity compared to other causes of CKD. ARVD is typically associated with extensive extra-renal atherosclerosis and significant cardiovascular comorbidities; 91\% of ARVD patients have hypertension, 38\% have clinical heart failure, and $67 \%$ have coronary artery disease $[1,2]$.

As a result of these overlapping cardiovascular risk factors, cardiac structural remodelling is almost ubiquitous in ARVD. At least three-quarters of ARVD patients have left ventricular hypertrophy and diastolic dysfunction on echocardiography [3]. Patients with ARVD have $58 \%$ greater LV mass than eGFR matched CKD controls [3], and likewise greater LV mass than non-CKD hypertension controls [4].

Two large clinical trials failed to show clinical benefit of renal artery revascularization when used as first line therapy for ARVD. The primary outcome measure of the ASTRAL (Angioplasty and Stenting for Renal Artery Lesions) trial was longitudinal change in renal function, while that of the CORAL (Cardiovascular Outcomes in Renal Atherosclerotic Lesions) trial was a composite of death or major morbidity from cardiovascular or renal causes $[5,6]$.

Although revascularization does not benefit most patients, there are many documented cases of significant clinical and cardiac structural changes soon after intervention $[7,8]$. These suggest that revascularization may be of benefit either in specific ARVD sub-groups, or that patients undergo significant cardiac remodelling after renal artery revascularization that does not manifest as a reduction in the acute events recorded as end-points in clinical trials. Whilst reporting bias is certain in these reports, flash pulmonary oedema is the only clinical scenario that has attracted Class I recommendation for revascularization $[9,10]$.

Flash pulmonary oedema is however the presenting feature in only $12 \%$ of cases of ARVD [11], meaning that the majority of patients with ARVD do not appear to suffer acute decompensation of heart failure despite underlying cardiac remodelling. In these patients, any change in cardiac structure and function that may occur as a result of revascularization might not manifest as a reduction in the acute cardiovascular events measured by ASTRAL and CORAL. It is therefore reasonable to hypothesise that patients with ARVD and abnormal hearts who do not present with flash pulmonary oedema may show sub-clinical improvements in cardiac structure and function after revascularization compared to standard medical therapy [12, 13].

Here we present findings from an echocardiographic sub-study of the ASTRAL trial. The primary aim of this study was to evaluate whether the addition of renal artery revascularization to standard medical therapy led to improvements in the cardiac structural and functional abnormalities associated with ARVD, as found on echocardiography, compared to standard medical therapy alone. A secondary aim was to quantitatively describe the natural progression of cardiac abnormalities in an ARVD cohort, irrespective of therapy, and specifically in patients for whom revascularization is not already indicated.

\section{Methods}

The detailed method of patient selection and intervention for ASTRAL has previously been published [5]. In summary, ASTRAL was a multicentre, non-blinded clinical trial comparing outcomes in ARVD between patients randomised to receive either medical therapy or medical therapy plus percutaneous renal artery revascularization (Clinical Trials Registration ISRCTN59586944). Ethical approval for ASTRAL was granted by the West Midlands Multicentre Research Ethics Committee, UK and the ethics committee relevant to each individual participating study centre. Ethical permission for the echocardiographic sub-study was obtained separately. Support for the main ASTRAL trial was received from the Medical Research Council UK, Kidney Research UK, and Medtronic.

\section{Patient selection}

Patients were eligible for ASTRAL if they had at least one renal artery with an atherosclerotic lesion suitable for percutaneous revascularization and their managing clinician was not convinced that revascularization was essential. Patients were excluded if revascularization was already indicated as per guidelines, if the patient had undergone previous revascularization, or if the stenosis was not atherosclerotic in origin. No patients on haemodialysis were entered into the study, and because flash pulmonary oedema is a long-standing agreed indication for revascularization in ARVD, such patients were not recruited to ASTRAL.

Patients from 7 centres participating in ASTRAL were approached to take part in this cardiac sub-study (Salford Royal Hospital, Manchester Royal Infirmary, Royal Free London, Aberdeen Royal Infirmary, Derriford Hospital Plymouth, Glasgow Royal Infirmary, University Hospitals of Leicester). Patients were randomised 1:1 into the ASTRAL study to either revascularization or no revascularization, and this also determined the randomised treatment allocation of patients in the sub-study. No specific exclusion criteria were applied to the echocardiographic sub-study, and every patient provided signed informed consent. 


\section{Echocardiography protocol}

Patients underwent a full cross-sectional transthoracic echocardiogram within 6 weeks of enrolment and, if randomised to revascularization, before they underwent the procedure. A second transthoracic echocardiography was obtained 1 year later. Scans were performed locally at each participating centre by technicians accredited for transthoracic echocardiography by the British Society for Echocardiography. Interpretation was performed by a single imaging consultant cardiologist blind to the date of each scan and the participant's randomised treatment allocation.

All image acquisitions and measurements were performed as recommended by the American Society of Echocardiography [14] and have been described previously [15]. In brief, left ventricular end diastolic diameter (LVEDD), LV end systolic diameter (LVESD), interventricular and LV posterior wall thickness at end diastole were measured from parasternal long-axis $\mathrm{M}$ mode recordings of the LV. The modified biplane Simpson's rule was used to determine the LV ejection fraction, with measurements averaged over three cardiac cycles. Pulsed wave Doppler recordings at the mitral valve leaflet tips in the apical four-chamber view were used to record transmitral flow. Peak velocity of early filling (E), peak velocity of atrial filling (A), the E/A ratio, E-deceleration time (ms) and isovolumetric relaxation time (IVRT) were measured. LV mass was calculated using the Devereux Formula. LV regional wall motion was analysed visually using the standard 17-segment model for qualitative analysis and wall motion was scored on a 4 -point scale $(1=$ normal wall motion, $2=$ hypokinesis, $3=$ akinesis, and $4=$ dyskinesis). The wall motion score index was calculated as an average of the individual wall motion scores of each visualised segment. Echocardiographic evaluation of the aorta was performed in the parasternal long-axis and suprasternal view with measures recorded at the tubular ascending aorta. The severity of valve disease was determined by the physician's visual assessment and graded as mild, moderate or severe [16].

\section{Sample size}

Sample size calculation was based on left ventricular end diastolic diameter (LVEDD), one of the more sensitive parameters of change in cardiac function over time, or after intervention, and based upon change in LVEDD in a previous study of 79 ARVD patients (mean LVEDD $5.37 \pm 0.95 \mathrm{~cm}$ ). To detect a $0.6 \mathrm{~cm}$ (SD 0.95) difference between revascularization and control groups at a power of $80 \%, 41$ patients would be needed for each group with an alpha of 0.05 . At $90 \%$ power, patient numbers would be 54 per group.

\section{Statistical analysis}

The main end-points were change from baseline to follow up in each of the echocardiographic parameters listed above. The two treatment groups of medical therapy alone and medical therapy plus revascularization were compared using 2-sample t-tests. Multivariate linear regression models were then constructed to consider the effects of other pre-specified clinically relevant baseline variables on each of the echocardiographic parameters at 12 months. Alongside treatment group, the following variables were included in each model: age, presence of diabetes, history of coronary heart disease, systolic blood pressure, diastolic blood pressure, degree of stenosis to most affected kidney, renal function using eGFR, prescription of beta-blockers and renin angiotensin blockade and baseline ventricular measurement. A $p$-value of $<0.05$ was considered statistically significant. All analyses were performed using SAS version 9.1 (SAS Institute, Cary, NC, USA).

\section{Results}

There were 92 patients included in the study (50 medical, 42 revascularization). The two arms were broadly comparable: the age in the medical arm was 71 years (range 51-86) compared with 70 (53-86) years in the revascularization arm $(p=0.9)$. There was no difference in baseline eGFR, calculated using the CockroftGault equation: $43.0(17.0-79.7) \mathrm{ml} / \mathrm{min}$ versus 44.7 $(15.4-89.8) \mathrm{ml} / \mathrm{min}(p=0.65)$. Similarly, there was no difference in systolic blood pressure: 152 (90-220) $\mathrm{mmHg}$ versus $146(103-196) \mathrm{mmHg}(p=0.36)$. A full comparison of baseline characteristics is found in Table 1 . The only difference between the arms was that patients in the medical therapy group were more likely to be on lipid lowering therapy than those in the revascularization group (93\% versus $78 \%, p=0.04)$. However, serum cholesterol was no different: $4.5(2.8-7.9) \mathrm{mmol} /$ $\mathrm{L}$ versus $4.3(2.3-6.5) \mathrm{mmol} / \mathrm{L}, p=0.43$.

The baseline echocardiographic measurements were all comparable between groups, with none showing a statistically significant difference. Systolic function was well preserved overall $(54 \pm 10 \%)$. The complete list of baseline echocardiographic variables is found in Table 2 . This table also shows the change in each parameter between baseline and follow up. There was no difference between the medical and revascularization arms for longitudinal change in any echocardiographic parameter on univariate analysis. These are detailed in full in Table 2 . LVEF was closest to showing a statistical difference (medical $0.8 \pm 8.7 \%$ versus revascularization $-2.8 \pm 6.8 \%$, $p=0.05)$.

Importantly, allied to this, there was no change in blood pressure between arms during follow up. In the medical arm, the mean systolic blood pressure change 
Table 1 Baseline characteristics comparing medical therapy versus revascularization patients

\begin{tabular}{|c|c|c|c|}
\hline & Medical $(N=50)$ & Revascularization $(N=42)$ & $\mathrm{p}$ \\
\hline \multicolumn{4}{|l|}{ Demographic } \\
\hline Mean age (range) - years & $71(51-86)$ & $70(53-86)$ & 0.90 \\
\hline Male sex - no. (\%) & $34(68 \%)$ & 33 (79\%) & 0.26 \\
\hline \multicolumn{4}{|l|}{ Clinical } \\
\hline \multicolumn{4}{|l|}{ Smoking status - no./total no (\%) } \\
\hline Current smoker & $11 / 46(24 \%)$ & $8 / 36(22 \%)$ & 0.86 \\
\hline Former smoker & $24 / 46(52 \%)$ & 19/36 (53\%) & 0.96 \\
\hline \multicolumn{4}{|l|}{ Coexisting conditions - no./total no (\%) } \\
\hline Diabetes & $15 / 47(32 \%)$ & 13/37 (35\%) & 0.76 \\
\hline Coronary heart disease & 25/47 (53\%) & 22/37 (59\%) & 0.57 \\
\hline Peripheral vascular disease & $20 / 46(43 \%)$ & $17 / 37(46 \%)$ & 0.82 \\
\hline Stroke & $14 / 47(30 \%)$ & $8 / 37(22 \%)$ & 0.40 \\
\hline Need for dialysis & 0 & 0 & - \\
\hline \multicolumn{4}{|l|}{ Renal Function } \\
\hline Mean serum creatinine (range) - $\mu \mathrm{mol} /$ /itre & $165(64-326)$ & $170(68-534)$ & 0.76 \\
\hline Mean eGFR (range) - ml/min & $43.0(17.0-79.7)$ & $44.7(15.4-89.8)$ & 0.65 \\
\hline Mean proteinuria (range) - g/day & $0.45(0.01-2.20)$ & $0.42(0.00-1.70)$ & 0.90 \\
\hline \multicolumn{4}{|l|}{ Related Measures } \\
\hline Mean systolic BP (range) - mmHg & $152(90-220)$ & $146(103-196)$ & 0.36 \\
\hline Mean diastolic BP (range) - mmHg & $74(57-97)$ & $74(45-102)$ & 0.93 \\
\hline Mean total cholesterol (range) - mmol/litre & $4.5(2.8-7.9)$ & $4.3(2.3-6.5)$ & 0.43 \\
\hline \multicolumn{4}{|l|}{ Renal Physiology } \\
\hline Mean stenosis (range) - \% & $73.6(50-99)$ & $71.2(50-95)$ & 0.41 \\
\hline Severity of stenosis- no (\%) 50-70\% & $26(52 \%)$ & $25(60 \%)$ & 0.47 \\
\hline$>70 \%$ & $24(48 \%)$ & $17(40 \%)$ & - \\
\hline Mean bipolar kidney length (range) - cm & $9.6(7.0-11.9)$ & $9.7(6.4-12.5)$ & 0.70 \\
\hline \multicolumn{4}{|l|}{ Use of Concomitant medication } \\
\hline Mean no. of antihypertensive drugs (range) & $3.0(1-5)$ & $2.9(1-5)$ & 0.66 \\
\hline Any antiplatelet drug - no./total no. (\%) & $38 / 47(81 \%)$ & $31 / 37(84 \%)$ & 0.73 \\
\hline Lipid lowering therapy - no./total no. (\%) & $43 / 46(93 \%)$ & 29/37 (78\%) & 0.04 \\
\hline Warfarin - no./total no. (\%) & $2 / 47(4 \%)$ & 5/36 (14\%) & 0.12 \\
\hline
\end{tabular}

Key: $B P$ blood pressure, eGFR estimated glomerular filtration rate

during follow up was $0 \mathrm{mmHg}$ (range -56 to +54 $\mathrm{mmHg})$. This compared with a mean change of $-3(-61$ to +59$) \mathrm{mmHg}$ in the revascularization arm $(p=0.60)$. For diastolic blood pressure, the respective changes were $0(-27$ to +80$) \mathrm{mmHg}$ versus $-4(-41$ to +20$) \mathrm{mmHg}$ $(p=0.27)$.

Table 3 summarises the output of the multivariate regression models for each of the echocardiographic parameters. Treatment modality did not alter outcome for any echocardiographic parameter including left ventricular mass, volume and ejection fraction. Other baseline factors did demonstrate significance, particularly medication although no drugs were consistently significant across all echocardiographic parameters. Beta-blockade was associated with better aortic root diameter at follow up, but higher left ventricular mass and relative wall thickness. ACE inhibitor use was also associated with higher relative wall thickness.

When comparing all follow up scans with all baseline scans, there was no overall significant difference between any individual parameter using paired t-test: LVEF baseline $=54 \pm 10 \%$ versus LVEF at follow up $=53 \pm 9 \%$, $p=0.40$; left atrial diameter $=4.0 \pm 0.5 \mathrm{~cm}$ versus $4.0 \pm$ $0.6 \mathrm{~cm}, p=0.19$; LVEDD $=4.9 \pm 0.4$ versus $4.8 \pm 0.4, p=$ $0.07, \mathrm{LV}$ mass $=206 \pm 37 \mathrm{~g}$ versus $204 \pm 37 \mathrm{~g}, p=0.65$. Although the overall pattern was of no change, individual cases did show deterioration or improvement in 
Table 2 Comparison of echocardiographic parameters at baseline between trial arms and comparison of the changes in measurement on the follow up scans compared to baseline

\begin{tabular}{|c|c|c|c|c|c|}
\hline & \multicolumn{2}{|l|}{ Baseline } & \multicolumn{3}{|c|}{ Change at follow up } \\
\hline & Medical & Revasc & Medical & Revasc & $p$ \\
\hline Aortic root diameter $(\mathrm{cm})$ & $3.1 \pm 0.4$ & $3.1 \pm 0.4$ & $0.002 \pm 0.3$ & $0.06 \pm 0.3$ & 0.4 \\
\hline LVOT velocity (m/s) & $1.2 \pm 0.2$ & $1.2 \pm 0.2$ & $-0.02 \pm 0.1$ & $-0.03 \pm 0.1$ & 0.7 \\
\hline LV ejection fraction (\%) & $53.8 \pm 10.5$ & $53.6 \pm 9.2$ & $0.8 \pm 8.7$ & $-2.8 \pm 6.8$ & 0.05 \\
\hline Left atrial diameter (cm) & $3.8 \pm 0.5$ & $3.9 \pm 0.5$ & $0.1 \pm 0.4$ & $0.01 \pm 0.5$ & 0.3 \\
\hline LVESD (cm) & $2.8 \pm 0.6$ & $2.8 \pm 0.5$ & $-0.07 \pm 0.4$ & $0.1 \pm 0.6$ & 0.1 \\
\hline LVEDD (cm) & $4.9 \pm 0.4$ & $4.9 \pm 0.4$ & $-0.08 \pm 0.4$ & $-0.07 \pm 0.4$ & 0.9 \\
\hline Left ventricular mass (g) & $203 \pm 37$ & $202 \pm 34$ & $-2.9 \pm 33$ & $-1.7 \pm 39$ & 0.9 \\
\hline Relative wall thickness & $0.45 \pm 0.08$ & $0.44 \pm 0.06$ & $0.01 \pm 0.06$ & $0.01 \pm 0.06$ & 0.98 \\
\hline$E: A$ & $1.1 \pm 0.6$ & $1.1 \pm 0.6$ & $-0.0005 \pm 0.6$ & $0.03 \pm 0.7$ & 0.8 \\
\hline E deceleration time (ms) & $206 \pm 59$ & $202 \pm 66$ & $-1.1 \pm 55.5$ & $-9.0 \pm 70.2$ & 0.6 \\
\hline
\end{tabular}

Data are mean \pm standard deviation

Key: revasc revascularization arm, LVOT left ventricular outflow tract, $L V$ left ventricular, ESD end systolic diameter, EDD end diastolic diameter, $n / s$ not significant

structure or function on echocardiography, albeit without a difference between the treatment arms as outlined above. The range of change in LVEF was -19 to $+27 \%$ (median 0\%), for left atrial diameter was $-1.1 \mathrm{~cm}$ to +1.4 $\mathrm{cm}$ (median $0 \mathrm{~cm}$ ), for LVEDD was $-0.9 \mathrm{~cm}$ to $+1.0 \mathrm{~cm}$ (median $-0.1 \mathrm{~cm}$ ), and for LV mass was $-101 \mathrm{~g}$ to $+129 \mathrm{~g}$ (median $0 \mathrm{~g}$ ).

Figure 1 shows the correlation between baseline measurements of LVEF, left atrial diameter, LVEDD and LV mass, and the change in these parameters at follow up

Table 3 Factors associated with echocardiographic measurements at follow up based on multivariate analysis

\begin{tabular}{|c|c|c|c|c|c|}
\hline Measurement & Significant factors & Estimate & Standard Error & $95 \% \mathrm{Cl}$ & $\mathrm{p}$ \\
\hline \multirow[t]{2}{*}{ AoRD } & Baseline AoRD & 0.83 & 0.08 & 0.66 to 0.99 & $<0.0001$ \\
\hline & Beta-blocker use - No & 0.20 & 0.07 & 0.07 to 0.34 & 0.004 \\
\hline LVOT velocity & Baseline LVOT velocity & 0.73 & 0.08 & 0.58 to 0.88 & $<0.0001$ \\
\hline LVEF & Baseline LVEF & 0.61 & 0.08 & 0.45 to 0.77 & $<0.0001$ \\
\hline LA diameter & Baseline LA diameter & 0.88 & 0.11 & 0.67 to 1.10 & $<0.0001$ \\
\hline LVESD & Baseline LVESD & 0.51 & 0.08 & 0.34 to 0.67 & $<0.0001$ \\
\hline \multirow[t]{2}{*}{ LVEDD } & Baseline LVEDD & 0.52 & 0.08 & 0.35 to 0.68 & $<0.0001$ \\
\hline & Age & -0.01 & 0.005 & -0.02 to -0.0003 & 0.04 \\
\hline \multirow[t]{4}{*}{ LV mass } & Baseline LV mass & 0.60 & 0.09 & 0.42 to 0.77 & $<0.0001$ \\
\hline & Coronary heart disease - No & 20.1 & 6.54 & 7.02 to 33.19 & 0.003 \\
\hline & eGFR & -0.49 & 0.20 & -0.89 to -0.09 & 0.02 \\
\hline & ACE inhibitor use - No & -13.2 & 6.26 & -25.74 to -0.68 & 0.04 \\
\hline \multirow[t]{2}{*}{$\mathrm{E}: \mathrm{A}$} & Baseline E:A & 0.38 & 0.11 & 0.15 to 0.61 & 0.002 \\
\hline & Diabetes - No & -0.30 & 0.14 & -0.58 to -0.01 & 0.04 \\
\hline \multirow[t]{3}{*}{ EDT } & Baseline EDT & 0.40 & 0.10 & 0.20 to 0.59 & 0.0001 \\
\hline & Age & 1.99 & 0.95 & 0.08 to 3.89 & 0.04 \\
\hline & eGFR & 0.93 & 0.38 & 0.17 to 1.68 & 0.01 \\
\hline \multirow[t]{3}{*}{ RWT } & Baseline RWT & 0.68 & 0.08 & 0.51 to 0.84 & $<0.001$ \\
\hline & Beta-Blocker use - No & -0.02 & 0.01 & -0.04 to -0.001 & 0.04 \\
\hline & ACE inhibitor use - No & -0.03 & 0.01 & -0.06 to -0.01 & 0.003 \\
\hline
\end{tabular}

Key: LVOT left ventricular outflow tract, $L V E F$ left ventricular ejection fraction, $L A$ left atrium, LVESD left ventricular end systolic diameter, $L V E D D$ left ventricular end diastolic diameter, EDT E wave deceleration time, RWT relative wall thickness, Cl confidence intervals, eGFR estimated glomerular filtration rate, AoRD aortic root diameter Each model included the following variables: treatment group, age, presence of diabetes, history of coronary heart disease, systolic blood pressure, diastolic blood pressure, degree of stenosis to most affected kidney, renal function using eGFR, prescription of beta-blockers and renin angiotensin blockade and the baseline ventricular measurement 

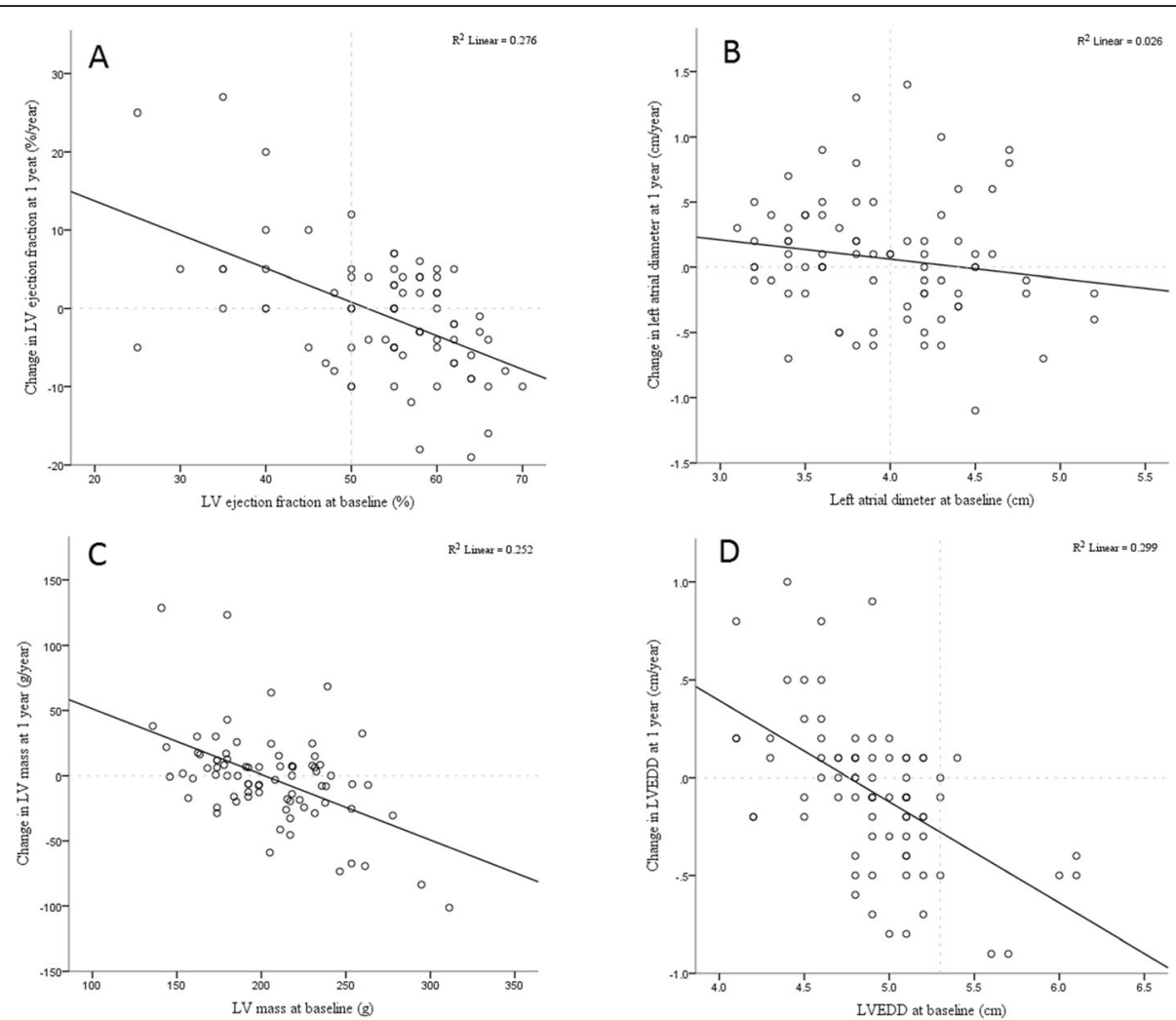

Fig. 1 Correlation between change in echocardiographic measurements at 1 year compared to baseline measurement for a) left ventricular (LV) ejection fraction, b) left atrial diameter, c) left ventricular mass, d) left ventricular end diastolic diameter (LVEDD)

compared to baseline. For LVEF, 54\% of patients with preserved systolic function at baseline (LVEF $\geq 50 \%)$ had a worse LVEF at follow up. This compared with $24 \%$ of patients who had pre-existing systolic impairment at baseline $(\mathrm{LVEF}<50 \%)$. The correlation coefficient between baseline LVEF and change in LVEF was - 0.53, $p<0.01$.

In a between group comparison of dLVEF between those with preserved baseline LVEF ( $\geq 50 \%$ versus those with reduced LVEF $(<50 \%)$ at baseline, the mean change in the preserved function group was $-2.4 \pm 6.4 \mathrm{~mL}$ versus $+5.2 \pm 10.5 \mathrm{~mL}$ in the reduced function group $(p=0.01)$. The distribution was parametric.

For LA diameter, $54 \%$ of patients with a dilated left atrium (diameter $>4 \mathrm{~cm}$ ) at baseline showed an improvement in diameter at follow up. The figure for baseline normal left atrium was $25 \%$. For change in left atrial diameter against baseline reading, the correlation coefficient was $-0.16, p=0.16$. Only 5 patients had LVEDD $>5.3 \mathrm{~cm}$ at baseline but all of these showed improvement at follow up. Change in left ventricular mass followed a similar pattern to that of LVEF (Fig. 1).

In a between group comparison of change in left atrial diameter between those with normal baseline diameter $(<4.0 \mathrm{~cm})$ versus those with increased diameter $(\geq 4.0 \mathrm{~cm})$, the mean change in the normal group was $+0.1 \pm 0.4 \mathrm{~cm}$ versus $0.0 \pm 0.5 \mathrm{~cm}$ in the dilated group $(p=0.201)$.

\section{Discussion}

This sub-study of a randomised clinical trial included 92 patients with ARVD and did not show any difference in longitudinal change in echocardiographic parameters between patients treated with renal artery revascularization versus those given medical therapy alone. This is consistent with the cardiovascular end point findings of the main ASTRAL [5] (hazard ratio for cardiovascular events $0.94,95 \%$ CI $0.75-1.19, p=0.61$ ) and CORAL [6] studies (hazard ratio for composite primary end-point 0.94; 95\% CI 0.76-1.17; $p=0.58$ ).

Our findings are consistent with two other randomised clinical trials. A recent parallel ASTRAL sub-study investigated the effects of revascularization on cardiac structure and function using cardiac magnetic resonance imaging in 18 patients treated exclusively medically and 23 patients who underwent revascularization in addition to treatment with medical therapy. Although slight improvements in cardiac structural parameters were seen in both groups at 12 months follow-up, there were no significant differences between groups (change in 
LVM in medical versus revascularized group: $-5.4 \mathrm{~g}$ versus $-6.3 \mathrm{~g}, p=0.8$ ) [17]. The stenting of Renal Artery Stenosis in Coronary Artery Disease (RAS-CAD) study is another randomised trial that explored the effect of revascularization on LVMI in ARVD patients with mean renal artery stenosis $<70 \%$, mean eGFR $>60.0 \mathrm{ml} / \mathrm{min} /$ $1.73 \mathrm{~m}^{2}$ and well-controlled blood pressure; patients in both arms were established on multi-targeted medical therapy. Revascularization was shown to have no additional impact on cardiac structure and blood pressure control beyond optimal medical therapy. However, there was again significant equivalent improvement in blood pressure control and LVMI in both revascularized $(n=43)$ and non-revascularized patients $(n=41)$ [18].

In contrast, in our study there was no overall difference in parameters at follow up compared to baseline. Previous small non-randomised studies had demonstrated improvement in left ventricular mass in patients with renovascular hypertension or haemodynamically significant stenosis. In two of these studies, this was shown to correlate with improvement in blood pressure control $[19,20]$. In ASTRAL, including this sub-study, there was no difference in blood pressure control between treatment arms. This likely explains the lack of any difference in $\delta \mathrm{LVM}$ seen here.

Although a lack of longitudinal improvement was noted in this study, which differs from the results of ASTRAL cardiac magnetic resonance imaging sub-study and RAS-CAD $[17,18]$, this is not surprising given the relative insensitivity of transthoracic echocardiography for certain measurements (e.g. LV mass) compared to cardiac magnetic resonance imaging. Left ventricular mass was not adjusted for height and weight due to missing data hence this may also have contributed to reduced accuracy. Regardless, the outcome measurement is change in cardiac mass over time for each individual patient. Given this, it is unlikely that there would be any additional benefit to indexing these measurements against body surface area or height.

In view of the lack of measurable longitudinal changes observed in our study, we support the current view that optimised medical therapy is as effective as revascularization for routine ARVD therapy, except in those patients for whom revascularization is already indicated. Indeed, in the current study we provided examples of patients who showed definite improvement or stabilisation in echocardiographic parameters at 1 year, and likewise some with evidence of deterioration and this is of clinical importance. This comment is made notwithstanding the possibility that the longitudinal changes seen represent regression to the mean in a population with a broad baseline measurement in echocardiographic descriptors.
Our results suggest a weak inverse correlation between baseline function and improvement at 1 year, in keeping with results from observational studies showing that revascularization only appears to be of benefit in a small subset of 'high-risk' patients [11, 21, 22]. Future research efforts are likely to be directed towards the timely identification of these individuals through risk stratification techniques with the aim of improving patient selection for revascularization.

In our study, beta-blockade was associated with reduction in aortic root diameter. In light of the predominance of diastolic dysfunction in patients with ARVD [3], this is presumed to be a function of blood pressure reduction and consequent improved diastolic function, though we have no direct evidence of causation from this trial. Beta-blockers have been consistently shown to prevent adverse cardiac remodelling and optimise clinical outcomes in patients with reduced ejection fractions [23-25], although there is a concern that in patients with heart failure with preserved ejection fraction (HFpEF) beta-blockers can precipitate a negative chronotropic effect and reduced exercise tolerance [26]. Their value in patients with non-ischaemic heart failure with preserved ejection fraction has however not been studied. Given the upregulated sympathetic drive and the high rate of co-existent cardiovascular disease in ARVD patients [1], our findings point towards the use of such therapy in these patients. Indeed, a recent retrospective analysis performed on 529 patients with ARVD showed that over a median follow-up period of 3.8 years, beta-blockade was associated with reduced risk of death (relative risk 0.52 [95\% CI 0.31-0.89], $p=0.02$ ) and nonfatal cardiovascular events (relative risk 0.74 [95\% CI $0.60-0.90], p=0.003)$ [27].

In the context of non-ARVD patients with hypertension and diastolic dysfunction without a clinical diagnosis of heart failure, angiotensin-receptor blockers have been shown to reduce left ventricular mass and function and improve exercise tolerance; the changes in RWT observed in this study did not mirror this [28-30], but renin-angiotensin blockade has been shown to be associated with improved clinical outcomes in observational studies carried out in patients with ARVD [31, 32]. Given the existing knowledge of the pathophysiology of diastolic dysfunction in these patients, renin-angiotensin blockade remains part of the standard of care for these patients.

This study has limitations. Due to the slightly lower than expected number of patients, the study had $80 \%$, rather than $90 \%$, power to detect differences of the anticipated magnitude. Finally, as mentioned above, an important consideration is that some patients recruited into this study may have had clinical and haemodynamically insignificant RAS and so these results are not 
necessarily generalizable to all patients with ARVD, particularly those with severe renal artery stenosis presenting with heart failure and other high-risk clinical phenotypes [11].

\section{Conclusion}

In this ASTRAL sub-study, there was no significant difference in longitudinal change in echocardiographic parameters between revascularized and non-revascularized patients, nor between baseline and follow-up scans in the study population as a whole. These results are consistent with the neutral renal, cardiovascular and mortality end-points observed in the main ASTRAL trial and in the subsequent CORAL trial.

\begin{abstract}
Abbreviations
A: Peak velocity of atrial filling; ACE: Angiotensin converting enzyme; AoRD: Aortic root diameter; ARVD: Atherosclerotic renovascular disease; ASTRAL: Angioplasty and Stenting for Renal Artery Lesions; Cl: Confidence intervals; CKD: Chronic kidney disease; CORAL: Cardiovascular Outcomes in Renal Atherosclerotic Lesions; E: Peak velocity of early filling; EDT: E wave deceleration time; eGFR: Estimated glomerular filtration rate.; FGF23: Fibroblast growth factor-23; IVRT: Isovolumetric relaxation time; LV: Left ventricle; LVEDD: Left ventricular end diastolic diameter " LVEF: Left ventricular ejection fraction; LVESD: Left ventricular end systolic diameter; LVM: Left ventricular mass; LVOT: Left ventricular outflow tract; PDGF: Platelet derived growth factor; RAS-CAD: Renal artery stenosis coronary artery disease; RWT: Relative wall thickness; TGF- $\beta$ : Transforming growth factor beta

\section{Acknowledgements}

The authors would like to thank the research nurses at the various sites for their help with patient recruitment and retention and for their valuable contribution to this project.
\end{abstract}

\section{Authors' contributions}

DG - performed data collection and analysis, and drafted the manuscript. DG had full access to study data and final responsibility for the decision to submit the publication. DV - assisted in drafting manuscript and revised manuscript for intellectual content. KH, KW, NI - data analysis and interpretation, statistical support and revised manuscript for intellectual content. RS - performed all of the blinded echo analyses. CC, JH, JW, JM, RP, CD, JW, PR, SC, JC, JO, PM, RS - patient recruitment, organization of echocardiographic analyses, revised manuscript for intellectual content. PK - study principal investigator, study conception and design, data analysis and interpretation, draft preparation and revised manuscript for intellectual content. All authors have read and approved the final version of the manuscript.

\section{Funding}

Support for the main ASTRAL trial was received from the Medical Research Council UK, Kidney Research UK, and Medtronic. These funding bodies had no role in study design, data collection, analyses, and interpretation, nor in writing the manuscript of this echocardiographic sub-study.

\section{Availability of data and materials}

The data that support the findings of this study are available from the Birmingham Clinical Trials Unit and Salford Royal NHS Foundation Trust but restrictions apply to the availability of these data, which were used under license for the current study, and so are not publicly available. Data are however available from the authors upon reasonable request and with permission of the Birmingham Clinical Trials Unit and Salford Royal Research and Development Department.

\section{Ethics approval and consent to participate}

Ethical approval for ASTRAL was granted by the West Midlands Multicentre Research Ethics Committee, UK and the ethics committee relevant to each individual participating study centre. Ethical permission for the echocardiographic sub-study was obtained separately. Patient consent for participation in this sub-study was obtained separately from consent for the main trial, and included a specific patient information sheet and written consent form.

\section{Consent for publication}

Not applicable.

\section{Competing interests}

Dr. Patrick Mark is an Editorial Board Member for BMC Nephrology.

\section{Author details}

'Department of Renal Medicine, Salford Royal NHS Foundation Trust, Stott Lane, Salford M6 8HD, UK. ${ }^{2}$ University of Birmingham, Birmingham, UK. ${ }^{3}$ Manchester Foundation Trust, Manchester, UK. ${ }^{4}$ Western Infirmary, Glasgow, UK. ${ }^{5}$ Glasgow Royal Infirmary, Glasgow, UK. ${ }^{6}$ Aberdeen Royal Infirmary, Aberdeen, UK. ${ }^{7}$ Derriford Hospital, Plymouth, UK. ${ }^{8}$ University Hospitals of Leicester, Leicester, UK. ${ }^{9}$ Royal Free Hospital, London, UK. ${ }^{10}$ St George's Hospital, London, UK. ${ }^{11}$ Institute of Cardiovascular and Medical Science, University of Glasgow, Glasgow, UK.

Received: 19 December 2017 Accepted: 30 May 2019

Published online: 14 June 2019

\section{References}

1. Kalra PA, Guo H, Kausz AT, et al. Atherosclerotic renovascular disease in United States patients aged 67 years or older: risk factors, revascularization, and prognosis. Kidney Int. 2005;68(1):293-301. https://doi.org/10.1111/j. 1523-1755.2005.00406.x.

2. de Silva R, Loh H, Rigby AS, et al. Epidemiology, associated factors, and prognostic outcomes of renal artery stenosis in chronic heart failure assessed by magnetic resonance angiography. Am J Cardiol. 2007;100(2): 273-9. https://doi.org/10.1016/j.amjcard.2007.02.098.

3. Wright JR, Shurrab AE, Cooper A, Kalra PR, Foley RN, Kalra PA. Left ventricular morphology and function in patients with atherosclerotic Renovascular disease. J Am Soc Nephrol. 2005;16(9):2746-53. https://doi.org/ 10.1681/asn.2005010043

4. Zeller T, Rastan A, Schwarzwalder U, et al. Regression of left ventricular hypertrophy following stenting of renal artery stenosis. J Endovasc Ther. 2007;14(2):189-97 doi:1526-6028-14-2-189 [pii] \r10.1583/15451550(2007)14[189,ROLVHF]2.0.CO;2.

5. Wheatley K, Ives N, Gray R, et al. Revascularization versus medical therapy for renal-artery stenosis. N Engl J Med. 2009;361(20):1953-62.

6. Cooper C, Murphy T, Cutlip D, et al. Stenting and medical therapy for atherosclerotic renal-artery stenosis. New Engl J Med. 2014;370(1):13-22. https://doi.org/10.1056/NEJMoa1310753.

7. Chrysochou C, Schmitt M, Siddals K, Hudson J, Fitchet A, Kalra PA. Reverse cardiac remodelling and renal functional improvement following bilateral renal artery stenting for flash pulmonary oedema. Nephrol Dial Transplant. 2013;28(2):479-83. https://doi.org/10.1093/ndt/gfr745.

8. Missouris C, Buckenham T, Vallance P, MacGregor G. Renal artery stenosis masquerading as congestive heart failure. Lancet. 1993;341(8859):1521-2.

9. Parikh SA, Shishehbor MH, Gray BH, White CJ, Jaff MR. SCAl expert consensus statement for renal artery stenting appropriate use. Catheter Cardiovasc Interv. 2014:84(7):1163-71. https://doi.org/10.1002/ccd.25559.

10. Hirsch AT, Haskal ZJ, Hertzer NR, et al. ACC/AHA 2005 guidelines for the Management of Patients with Peripheral Arterial Disease (lower extremity, renal, mesenteric, and abdominal aortic): a collaborative report from the American Association for Vascular Surgery/Society for Vascular Surgery,* so. J Am Coll Cardiol. 2006;47(6):e1-e192. https://doi.org/10.1016/j.jacc.2006.02.024.

11. Ritchie J, Green D, Chrysochou C, Chalmers N, Foley RN. Kalra P a. high-risk clinical presentations in atherosclerotic renovascular disease: prognosis and response to renal artery revascularization. Am J Kidney Dis. 2014; 63(2):186-97.

12. De Silva R, Nikitin NP, Bhandari S, Nicholson A, Clark AL, Cleland JGF. Atherosclerotic renovascular disease in chronic heart failure: should we intervene? Eur Heart J. 2005;26(16):1596-605. https://doi.org/10.1093/ eurheartj/ehi304.

13. De Mello WC, Danser AH. Angiotensin II and the heart: on the Intracrine renin-angiotensin system. Hypertension. 2000;35(6):1183-8. https://doi.org/ 10.1080/09585199200000155. 
14. Schiller N, Shah P, Crawford M, et al. Recommendations for quantitation of the left ventricle by two-dimensional echocardiography. American Society of Echocardiography Committee on Standards, Subcommittee on Quantitation of Two-Dimensional EchocardiogramsRecommendations for quantitation of th. J Am Soc Echocardiogr. 1989;2(5):358-67.

15. O'Driscoll JM, Gargallo-Fernandez P, Araco M, Perez-Lopez M, Sharma R Baseline mitral regurgitation predicts outcome in patients referred for dobutamine stress echocardiography. Int J Cardiovasc Imaging. 2017;33(11): 1711-21.

16. Gottdiener J, Panza J, St John Sutton M, Bannon P, Kushner H, Weissman N. Testing the test: the reliability of echocardiography in the sequential assessment of valvular regurgitation. Am Heart J. 2002;144(1):115-21.

17. Ritchie J, Green D, Chrysochou T, et al. Effect of renal artery revascularization upon cardiac structure and function in atherosclerotic renal artery stenosis: cardiac magnetic resonance sub-study of the ASTRAL trial. Nephrol Dial Transplant. 2016:gfw107. https://doi.org/10.1093/ndt/gfw107.

18. Marcantoni C, Zanoli L, Rastelli S. Effect of renal artery stenting on left ventricular mass: a randomised clinical trial. Am J Kidney Dis. 2012;60(1):39-46.

19. Symonides B, Chodakowska J, Januszewicz A, et al. Effects of the correction of renal artery stenosis on blood pressure, renal function and left ventricular morphology. Blood Press. 1999;8(3):141-50.

20. Yoshitomi Y, Nishikimi T, Abe H, et al. Comparison of changes in cardiac structure after treatment in secondary hypertension. Hypertension. 1996; 27(3 (Pt 1):319-23.

21. Vassallo D, Ritchie J, Green D, Chrysochou C, Kalra PA. The effect of revascularization in patients with anatomically significant atherosclerotic renovascular disease presenting with high-risk clinical features. Nephrol Dial Transpl. 2017;:Epub ahead. https://doi.org/10.1093/ndt/gfx025.

22. Green D, Ritchie JP, Chrysochou C, Kalra PA. Revascularization of atherosclerotic renal artery stenosis for chronic heart failure versus acute pulmonary oedema. Nephrol. 2017:Epub ahead of print. https://doi.org/10. 1111/nep.13038.

23. Andersson C, Shilane D, Solomon MD. Beta-blocker therapy and cardiac events among patients with newly diagnosed coronary heart disease. J Am Coll Cardiol. 2014;64(3):247-52. https://doi.org/10.1016/j.jacc.2014.04.042.

24. Waagstein F, Stromblad O, Andersson B, et al. Increased exercise ejection fraction and reversed remodeling after long- term treatment with metoprolol in congestive heart failure : a randomized, stratified, doubleblind, placebo-controlled trial in mild to moderate heart failure due to ischemic or. Eur J Hear Fail Fail. 2003;5(5):679-91. https://doi.org/10.1016/ S1388-9842.

25. Packer $M$, Fowler MB, Roecker EB, et al. Clinical investigation and reports effect of carvedilol on the morbidity of patients with severe chronic heart failure. Circulation. 2002;106(17):2194-9. https://doi.org/10.1161/01.CIR. 0000035653.72855.BF.

26. From AM, Borlaug BA. Heart failure with preserved ejection fraction: pathophysiology and emerging therapies. Cardiovasc Ther. 2011;29(4):6-21. https://doi.org/10.1111/j.1755-5922.2010.00133.x.

27. Ritchie J, Green D, Alderson HV, et al. Associations of antiplatelet therapy and beta blockade with patient outcomes in atherosclerotic renovascular disease. J Am Soc Hypertens. 2015:1-10. https://doi.org/10.1016/j.jash.2015.12.002.

28. Devereux RB, Dahlöf B, Gerdts E, et al. Regression of hypertensive left ventricular hypertrophy by losartan compared with atenolol: the losartan intervention for endpoint reduction in hypertension (LIFE) trial. Circulation. 2004;110(11):1456-62. https://doi.org/10.1161/01.CIR.0000141573.44737.5A.

29. Little WC, Zile MR, Klein A, Appleton CP, Kitzman DW, Wesley-Farrington DJ. Effect of losartan and hydrochlorothiazide on exercise tolerance in exertional hypertension and left ventricular diastolic dysfunction. Am J Cardiol. 2006;98(3):383-5. https://doi.org/10.1016/j.amjcard.2006.01.106.

30. Solomon SD, Janardhanan $\mathrm{R}$, Verma $A$, et al. Effect of angiotensin receptor blockade and antihypertensive drugs on diastolic function in patients with hypertension and diastolic dysfunction: a randomised trial. Lancet. 2007; 369(9579):2079-87. https://doi.org/10.1016/S0140-6736(07)60980-5.

31. Chrysochou C, Foley RN, Young JF, Khavandi K, Cheung CM, Kalra P. a. Dispelling the myth: the use of renin-angiotensin blockade in atheromatous renovascular disease. Nephrol Dial Transplant. 2012;27(4):1403-9. https://doi.org/10.1093/ndt/gfr496.

32. Losito A, Errico R, Santirosi P, Lupattelli T, Scalera GB, Lupattelli L. Long-term follow-up of atherosclerotic renovascular disease. Beneficial effect of ACE inhibition. Nephrol Dial Transplant. 2005;20(8):1604-9.

\section{Publisher's Note}

Springer Nature remains neutral with regard to jurisdictional claims in published maps and institutional affiliations.
Ready to submit your research? Choose BMC and benefit from:

- fast, convenient online submission

- thorough peer review by experienced researchers in your field

- rapid publication on acceptance

- support for research data, including large and complex data types

- gold Open Access which fosters wider collaboration and increased citations

- maximum visibility for your research: over $100 \mathrm{M}$ website views per year

At BMC, research is always in progress.

Learn more biomedcentral.com/submissions 